\title{
Cultivo de tamarindo sob malhas coloridas: plasticidade anatômica foliar
}

\author{
Tamarind cultivation under colored shading nets: leaf anatomical plasticity
}

\section{Renata Alves Lara Silva ${ }^{I^{*}}$ Joyce Dória Rodrigues Soares ${ }^{\mathrm{I}}$ Gabrielen de Maria Gomes Dias ${ }^{\mathrm{I}}$ Moacir Pasqual ${ }^{\mathrm{I}}$ Edvan Alves Chagas ${ }^{\text {II }}$ Manuel Losada Gavilanes ${ }^{\text {II }}$}

\section{RESUMO}

Este trabalho teve como objetivo avaliar o efeito da alteração da qualidade espectral da luz, utilizando malhas de transmissão de luz diferenciada, sobre características da anatomia foliar em plantas de tamarindo (Tamarindus indica L.), visando à obtenção de plantas mais propícias ao plantio. Mudas de tamarindo foram cultivadas sob malhas de $50 \%$ de sombreamento nas cores branca, azul, vermelha e preta em delineamento inteiramente casualizado. Após 90 dias de cultivo sob as malhas, as folhas foram avaliadas quanto à anatomia e micromorfologia. Plantas submetidas ao cultivo sob malha branca apresentaram maior altura das células da epiderme na face abaxial e maior espessura do parênquima paliçádico e da nervura central. Melhores resultados para epiderme na face adaxial e limbo foliar foram observados sob malhas branca e azul. Maiores densidades estomáticas foram obtidas sob malhas azul e vermelha. As folhas de Tamarindus indica apresentam plasticidade anatômica em resposta às modificações no espectro da radiação. Em face desses resultados, as malhas branca e azul podem ser recomendadas para obtenção de plantas mais propícias ao plantio.

Palavras-chave: Tamarindus indica, qualidade espectral, ambiente, formação de mudas.

\section{ABSTRACT}

This study aimed to evaluate the effect of changing light spectral quality, using colored shading nets, on the characteristics of tamarind (Tamarindus indica L.) leaf anatomy to obtain more conducive plants. Tamarind seedlings were grown under blue, white, black and red shade nets, in a completely randomized design. After 90 days, the leaves were evaluated anatomically and micromorphologically. Plants grown under white net had greater palisade parenchyma, abaxial epidermis cells and midrib thicknesses. Better results for adaxial epidermis and leaf blade were observed under white and blue nets. Higher stomatal density was obtained under blue and red nets. Tamarindus indica leaves present anatomical plasticity in response to changes in the radiation spectrum. In view of these results, the white and blue nets can be recommended to obtain plants more efficient to planting.

Key words: Tamarindus indica, spectral quality, environment, seedlings formation.

\section{INTRODUÇÃO}

A luz é considerada fonte de energia para os organismos fotossintéticos, os quais possuem aparatos minuciosamente arranjados para coletála de forma eficiente. A qualidade da luz incidente interfere, direta ou indiretamente, no funcionamento do aparelho fotossintético, fazendo com que este necessite se adaptar à luz predominante de um determinado ambiente, processo conhecido como aclimatação fotossintética à luz (WESTON et al., 2000). Essa aclimatação envolve uma variedade de respostas das plantas, dentre as quais estão incluídas as modificações na anatomia foliar (WESTON et al., 2000; TAIZ \& ZEIGER, 2013). Qualquer variação na estrutura da folha pode afetar as funções vegetais, como a densidade estomática, extensão e forma do mesofilo e diferenciação do sistema vascular, que, além de alterar trocas gasosas, distribuição e teor de pigmentos, também altera a dureza foliar e o balanço de carbono (LEE et al., 2000). De forma geral, os estudos sobre a estrutura foliar auxiliam

\footnotetext{
'Departamento de Agricultura, Universidade Federal de Lavras (UFLA), Campus UFLA, CP 3037, 37200-000, Lavras, MG, Brasil. E-mail: renata_vga@yahoo.com.br.*Autor para correspondência.

"Embrapa Roraima, Distrito Industrial, Boa Vista, RR, Brasil.

IIIDepartamento de Biologia, UFLA, Lavras, MG, Brasil. 
no entendimento das diferenças encontradas no crescimento das plantas (WESTON et al., 2000).

O tamarindo (Tamarindus indica L.) é uma espécie pertencente à família Fabaceae, subfamília Caesalpinoideae, sendo originário da África Tropical, de onde se dispersou. No Brasil, as plantas são bem adaptadas e subespontâneas em vários Estados, sendo encontradas em plantações dispersas, como ocorre na região Nordeste, onde o tamarindo é considerado fruto típico (SOUSA et al., 2010). É uma planta arbórea, multiuso, sendo considerada importante fonte alimentícia, devido à polpa do fruto, que pode ser consumida in natura ou utilizada no preparo de sucos, sorvetes, licores e doces (FERREIRA et al., 2008). Diversos estudos também apontam atividades farmacológicas relacionadas à espécie, dentre estas, antiinflamatória e analgésica (SURALKAR et al., 2012) e no tratamento de dores de cabeça e sintomas de stress, por meio de compressas ou banhos (SOUZA et al., 2010).

Segundo FERREIRA et al. (2008), as informações sobre a produção de mudas de tamarindo ainda são bastante escassas, sendo realizada de forma, muitas vezes, sem caráter científico. Ademais, a produção de mudas é um dos meios para a exploração técnica e comercial dessa espécie e, por ser uma cultura perene, essa etapa deverá ser conduzida com cuidado, a fim de se evitar problemas que poderão comprometer o período de exploração da cultura (GÓES et al., 2011). Assim, o estudo anatômico pode ser um aliado no estabelecimento e otimização do processo de formação de mudas de $\boldsymbol{T}$. indica, por fornecer evidências do comportamento fisiológico da planta em vários ambientes.

$\mathrm{Na}$ literatura não existem relatos a cerca do cultivo de tamarindo em ambientes com diferentes qualidades de luz, o que pode ser encontrado em abundância para outras espécies (OLIVEIRA et al., 2009; HUNSCHE et al., 2010b; SOLOMAKHIN \& BLANKE, 2010; SILVA et al., 2014). Estudos com esse propósito podem colaborar para a formação de mudas, que se constitui em etapa crucial do processo de produção e que pode possibilitar aos agricultores a obtenção, em viveiro, de plantas com melhor desempenho. Nesse contexto, o objetivo desse trabalho foi avaliar as modificações na anatomia foliar de plantas de tamarindo cultivadas sob malhas coloridas, visando a definir o ambiente mais propício para o cultivo de mudas dessa espécie.

\section{MATERIAL E MÉTODOS}

Condições de instalação e material vegetal utilizado - $\mathrm{O}$ experimento foi conduzido no Departamento de Agricultura da Universidade Federal de Lavras, no período de dezembro de 2012 a março de 2013. O munícipio de Lavras situa-se a $21^{\circ} 14^{\prime} \mathrm{S}$ e $45^{\circ} 00^{\prime} \mathrm{W}$ GRW, com altitude de $918 \mathrm{~m}$, sul de Minas Gerais, e, segundo a classificação de Köppen, o clima regional é do tipo Cwa com duas estações bem definidas, uma fria e seca, de abril a setembro, e outra quente e úmida, de outubro a março (BRASIL, 1992). Sementes provenientes de plantas adultas localizadas na região da Serra de Ibiapaba - CE foram semeadas em sacos plásticos contendo substrato Plantmax ${ }^{\circledR}$ e mantidas em sala de germinação durante 60 dias. Após esse período, as mudas foram alocadas sob estruturas de madeira cobertas com malhas de $50 \%$ de sombreamento nas cores branca, azul (Chromatinet ${ }^{\mathbb{R}}$ ), vermelha $\left(\right.$ Chromatinet $^{\mathbb{R}}$ ) e preta, por um período de 90 dias. Segundo o fabricante, a malha azul reduz ondas na faixa do vermelho e vermelho-distante e acrescenta ondas azuis, enquanto que a malha vermelha reduz ondas azuis, verdes e amarelas e acrescenta ondas nas faixas do vermelho e vermelho-distante. As malhas branca e preta não são fotoconversoras, de forma que a branca não interfere no espectro da luz transmitida e a preta não altera o espectro, apenas reduz a irradiância. Temperaturas máxima e mínima e fotoperíodo sob os quais os tratamentos foram submetidos variaram de acordo com as condições climáticas de Lavras no período. A irrigação foi diária e não houve adubação adicional.

Microscopia fotônica - Foram coletadas cinco folhas de plantas distintas, tomadas ao acaso em cada tratamento, das quais foram utilizados quatro folíolos de cada uma. Para maior padronização da coleta, optou-se por retirar as folhas localizadas no 5ํㅡó abaixo do ápice e, devido à folha ser composta, pinada e com variado número de folíolos, padronizouse a utilização dos folíolos centrais para o preparo de amostras para microscopia. As folhas foram previamente fixadas em F.A.A.70 (formaldeído + ácido acético + álcool 70\%) (JOHANSEN, 1940) e armazenadas, posteriormente, em etanol $70 \%$, e procedeu-se o seccionamento dos folíolos. Secções paradérmicas das faces abaxial e adaxial foram obtidas à mão livre, utilizando-se lâminas de aço inoxidável, enquanto as transversais foram feitas em micrótomo manual (Cidepe). As secções foram alvejadas em hipoclorito de sódio 1\% (JOHANSEN, 1940), e coradas com safranina $1 \%$ para secções paradérmicas e solução de safrablau (safranina 1\% e azul de astra 0,1\%) para secções transversais (BUKATSCH, 1972), sendo posteriormente montadas em lâminas semipermanentes com gelatina glicerinada. As lâminas foram observadas em microscópio, fotografadas e as medições foram realizadas no 
software ImageTool 3.0. Foram avaliados: densidade estomática, relação diâmetro polar/diâmetro equatorial dos estômatos e espessuras de células da epiderme, parênquima paliçádico, parênquima esponjoso, nervura central e limbo.

Microscopia eletrônica de varredura Fragmentos do terço médio dos folíolos centrais foram fixados em solução Karnovsky (KARNOVSKY, 1965), pós-fixados em solução de tetróxido de ósmio $1 \%$, desidratadas em soluções de concentrações crescentes de acetona e submetidas à secagem no aparelho de ponto crítico (BAL-TEC) (ROBARDS, 1978). As amostras secas foram montadas em stubs de alumínio e metalizadas com ouro em Sputtering (BAL-TEC). As amostras foram observadas em microscópio eletrônico de varredura (LEO, modelo EVO 40 XVP), segundo protocolo de ALVES (2004), em vista frontal, de ambas as faces da folha, e em secção transversal.

Delineamento experimental e análise estatística - Foi utilizado o delineamento inteiramente casualizado, com quatro tratamentos e cinco repetições, sendo cada repetição formada de quatro plantas. Os dados foram submetidos à análise de variância e as médias comparadas pelo teste de Scott-Knott, a 5\% de probabilidade, utilizando-se o programa estatístico SISVAR 4.3 (FERREIRA, 2011).

\section{RESULTADOS E DISCUSSÃO}

A folha de Tamarindus indica possui epiderme uniestratificada, com depósitos de cera epicuticular em ambas as faces do limbo, independente do tratamento adotado (Figura 1a), da

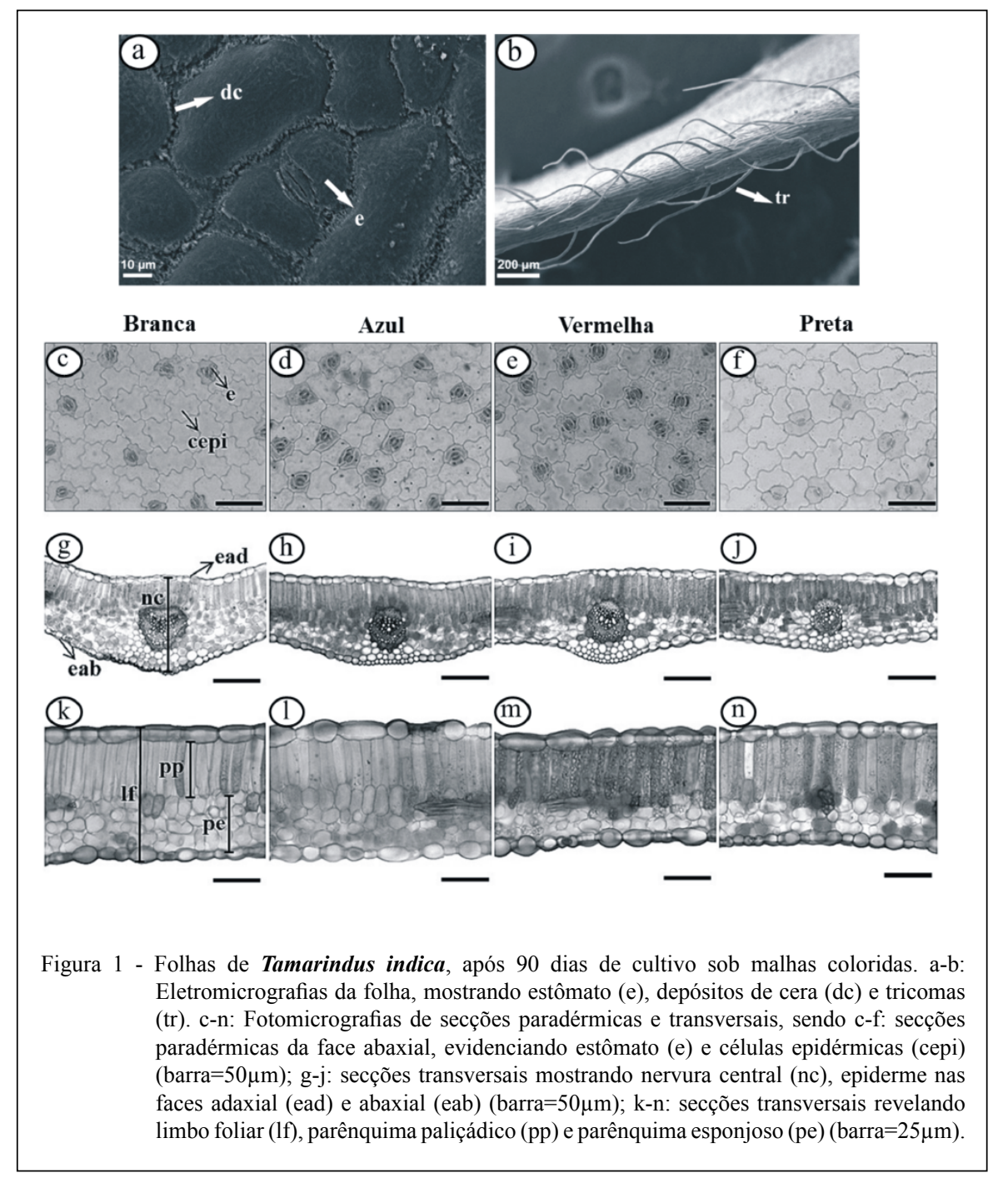

Ciência Rural, v.45, n.2, fev, 2015. 
mesma forma como foi observado por HUNSCHE et al. (2010a), revelando assim características hidrofóbicas. Tricomas tectores unicelulares de ápice agudo ocorrem somente no bordo do limbo, com provável função de proteção foliar (Figura 1b).

As malhas coloridas promoveram diferenças significativas na epiderme (Figura $1 \mathrm{c}-\mathrm{f}$ ), na espessura da nervura central (Figura 1 g-j), bem como na espessura do limbo foliar e dos parênquimas paliçádico e esponjoso (Figura 1 k-n).

Por meio da análise dos dados dos cortes transversais, foi possível observar que as plantas cultivadas sob malha branca apresentaram maior altura das células epidérmicas, tanto na face adaxial como na abaxial, quando comparados com os demais tratamentos (Tabela 1). Resultado similar foi encontrado em trabalho de SOLOMAKHIN \& BLANKE (2010), no qual plantas de maçã, quando cultivadas sob malhas fotoconversoras, apresentaram células da epiderme com menor altura. No caso da epiderme na face adaxial, a malha azul favoreceu altura das células significativamente igual àquela proporcionada pela malha branca. Em todas as malhas, o tamanho das células epidérmicas na face adaxial foi maior que na face abaxial (Tabela 1). De acordo com SHAHAK et al. (2004) e TAIZ \& ZEIGER (2013), a epiderme é caracterizada como sendo transparente à luz visível e suas células possuem paredes externas convexas, fazendo com que apresentem formato lenticular, de forma que elas podem atuar como lentes e concentrar a luz, fazendo que a quantidade de luz que atinge os cloroplastos possa ser muitas vezes maior que a do ambiente. No presente trabalho, as células epidérmicas também possuem formato convexo, porém, na malha branca, estas células são mais altas (Tabela 1), consequentemente menos luz chegará aos cloroplastos e o aparato fotossintético estará mais protegido contra danos causados pelo excesso de luz, sendo uma forma de plasticidade anatômica da epiderme (TAIZ \& ZEIGER, 2013).
Ainda com relação aos aspectos anatômicos relativos à epiderme, foram avaliadas a densidade estomática e a relação diâmetro polar/diâmetro equatorial dos estômatos, que são consideradas como características de alta plasticidade, quando do cultivo de plantas em ambientes com diferenças na qualidade espectral. Com relação às características estomáticas, segundo a literatura, a folha de tamarindo apresenta estômatos do tipo anomocítico e/ou paracítico em ambas as faces do limbo foliar, porém em maior densidade na face abaxial (TRIPATHI \& MONDAL, 2012), o que pôde ser observado no presente trabalho. $\mathrm{Na}$ face abaxial, maior densidade estomática foi obtida quando o cultivo foi feito sob malhas vermelha e azul (Figura 1 c-f). Já para a face adaxial, maior densidade foi observada nas malhas branca e preta (Tabela 2). Resultados similares foram encontrados por MARTINS et al. (2009) em alfavaca-cravo (Ocimum gratissimum L.), na qual maior número de estômatos foi registrado na face abaxial sob malha vermelha, enquanto que, na face adaxial, o cultivo sem malhas fotoconversoras foi responsável pela maior densidade. Estudos mostram que maior densidade estomática pode ser encontrada quando folhas são expostas à alta irradiação, dando indicações de melhor controle da condutância estomática, a qual irá reduzir as perdas de água por transpiração (ROSSATTO et al., 2009).

O cultivo das plantas sob malha preta favoreceu aumento da relação diâmetro polar/ diâmetro equatorial (DP/DE) em ambas as faces da epiderme, sendo que, para a face adaxial, a malha branca mostrou desempenho igual ao da malha preta (Tabela 2). A relação DP/DE do estômato oferece importante indicação sobre a funcionalidade desse anexo epidérmico. De acordo com KHAN et al. (2002), quanto maior a relação $\mathrm{DP} / \mathrm{DE}$, mais elipsoide é o estômato, podendo resultar em maior funcionalidade. As variações nas funcionalidades revelam a plasticidade anatômica de $\boldsymbol{T}$. indica $\mathrm{em}$

Tabela 1 - Espessuras do limbo foliar, da epiderme nas faces adaxial e abaxial e dos tecidos constituintes do mesofilo em plantas de Tamarindus indica, cultivadas sob malhas coloridas. Lavras, MG, 2013.

\begin{tabular}{|c|c|c|c|c|c|c|}
\hline Malha & Epiderme adaxial & Parênquima paliçádico & Parênquima esponjoso & Epiderme abaxial & Limbo foliar & Nervura central \\
\hline Azul & $13,68 \mathrm{a}$ & $43,80 \mathrm{~b}$ & $34,30 \mathrm{a}$ & $10,05 \mathrm{~b}$ & $99,89 \mathrm{a}$ & $128,90 \mathrm{~b}$ \\
\hline Vermelha & $11,57 \mathrm{~b}$ & $37,08 \mathrm{~d}$ & $27,64 \mathrm{~b}$ & $9,60 \mathrm{~b}$ & $84,85 \mathrm{c}$ & $129,31 \mathrm{~b}$ \\
\hline Branca & $13,80 \mathrm{a}$ & $47,67 \mathrm{a}$ & $29,74 \mathrm{~b}$ & 11,33 a & $102,16 \mathrm{a}$ & $134,65 \mathrm{a}$ \\
\hline Preta & $12,74 \mathrm{a}$ & $41,56 \mathrm{c}$ & $29,87 \mathrm{~b}$ & $10,31 \mathrm{~b}$ & $92,04 \mathrm{~b}$ & $119,79 \mathrm{c}$ \\
\hline $\mathrm{CV}(\%)$ & 13,29 & 13,06 & 15,61 & 17,61 & 4,43 & 5,48 \\
\hline
\end{tabular}

Médias seguidas da mesma letra na coluna não diferem entre si pelo teste de Scott-Knott, a 5\% de probabilidade.

Ciência Rural, v.45, n.2, fev, 2015. 
Tabela 2 - Densidade estomática (DS) e relação diâmetro polar/diâmetro equatorial (DP/DE) de plantas de Tamarindus indica, cultivadas sob malhas coloridas. Lavras, MG, 2013.

\begin{tabular}{|c|c|c|c|c|}
\hline Malha & DS adaxial & & DP/DE adaxial & DP/DE abaxial \\
\hline Azul & $20,00 \mathrm{~b}$ & $185,63 \mathrm{a}$ & $1,19 \mathrm{~b}$ & $1,13 \mathrm{~b}$ \\
\hline Vermelha & $20,05 \mathrm{~b}$ & $195,65 \mathrm{a}$ & $1,03 \mathrm{c}$ & $1,11 \mathrm{~b}$ \\
\hline Branca & $30,00 \mathrm{a}$ & $157,50 \mathrm{~b}$ & $1,37 \mathrm{a}$ & $1,19 \mathrm{~b}$ \\
\hline Preta & $30,63 \mathrm{a}$ & $131,25 \mathrm{c}$ & $1,27 \mathrm{a}$ & $1,46 \mathrm{a}$ \\
\hline CV (\%) & 16,94 & 16,92 & 14,01 & 12,34 \\
\hline
\end{tabular}

Médias seguidas da mesma letra na coluna não diferem entre si pelo teste de Scott-Knott, a 5\% de probabilidade.

função do ambiente de cultivo. Variações no tamanho e frequência de estômatos evidenciam a capacidade que as plantas possuem de rearranjar essas estruturas da epiderme em resposta às modificações ambientais, fazendo com que haja maior atuação dos estômatos nas trocas gasosas e transpiração, de forma adequada (ROSSATTO et al., 2009).

O mesofilo do tamarindeiro é caracterizado como dorsiventral, apresentando, em geral, parênquima paliçádico unisseriado, raramente com duas camadas de células (Figura 1 k-n). No presente trabalho, a espessura do parênquima paliçádico foi sempre maior que a do parênquima esponjoso, sendo que, para este último, maior espessura foi observada quando o cultivo ocorreu sob malha azul. Já para espessura do parênquima paliçádico, maiores valores foram obtidos sob malha branca, resultado que concorda com trabalho de OLIVEIRA et al. (2009) e SILVA et al. (2014), nos quais plantas de Artemisia vulgaris L. e de Musa sp., respectivamente, apresentaram maior espessura desse parênquima em cultivo na ausência de malhas fotoconversoras. Consequentemente, maiores valores para aumento do limbo foliar foram observados nas plantas cultivadas sob malhas azul e branca (Tabela 1; Figura $1 \mathrm{k}-\mathrm{n}$ ). O aumento da espessura do limbo é considerado estratégia de adaptação para melhorar a captação de energia luminosa e, por consequência, favorecer maior eficiência fotossintética (TAIZ \& ZEIGER, 2004). SILVA JÚNIOR et al. (2012) relataram maiores aumentos na espessura do limbo foliar em plantas de Laelia purpurata Lindl. sob cultivo com malha azul, enquanto que, para Ocimum selloi Benth, foi observado que o cultivo das plantas a pleno sol proporcionou maior espessura do limbo foliar (COSTA et al., 2010). Por tratar-se de uma planta heliófita, o tamarindo apresentou maior espessura de suas folhas na ausência de malhas fotoconversoras. De forma geral, plantas cultivadas a pleno sol, ambiente que é mais similar à malha branca, apresentam folhas mais espessas com células do parênquima paliçádico mais longas e justapostas (TAIZ \& ZEIGER, 2004).

Os resultados encontrados para a espessura do limbo evidenciam a importância da qualidade da luz sobre as características desse tecido foliar, como já relatado por muitos autores, sendo que, na maioria dos casos, observa-se redução da espessura foliar sob radiação vermelha (SCHUERGER et al., 1997). Neste trabalho, maior espessura foi obtida quando se utilizaram malhas azul e branca, sendo que a última não é considerada uma malha fotoconversora por não interferir no espectro da radiação, possuindo efeito similar à condição de pleno-sol. Sob essa malha, também foram obtidas as maiores espessuras para nervura central (Figura 1 g-j). De acordo com TAIZ \& ZEIGER (2004), a maior espessura do mesofilo é uma estratégia adaptativa que pode proporcionar maior eficiência fotossintética, devido a maiores ganhos de carbono proporcionados pela maior área foliar de captação da energia luminosa.

\section{CONCLUSÃO}

Folhas de tamarindo apresentam plasticidade anatômica em resposta as modificações no espectro da radiação. O cultivo feito sob malha branca proporciona maior altura das células da epiderme na face abaxial e maior espessura do parênquima paliçádico e da nervura central, enquanto que a altura das células da epiderme na face adaxial e espessura do limbo foliar foram igualmente maiores nas malhas branca e azul. Já as malhas vermelha e azul favorecem o aumento da densidade estomática. As malhas branca e azul podem ser recomendadas para o cultivo de mudas de tamarindo, pois elas favorecem o maior espessamento dos tecidos, 
que estão diretamente relacionados ao processo fotossintético.

\section{AGRADECIMENTOS}

Os autores agradecem ao Laboratório de Microscopia Eletrônica da Universidade Federal de Lavras (UFLA) pela possibilidade de realização das análises, a Fundação de Amparo à Pesquisa do estado de Minas Gerais (FAPEMIG) pelo recurso financeiro e ao Conselho Nacional de Desenvolvimento Científico e Tecnológico (CNPq) pela concessão da bolsa de estudo (Processo $\left.\mathrm{n}^{\mathrm{o}}: 140360 / 2012-3\right)$

\section{REFERÊNCIAS}

ALVES, E. Introdução à microscopia eletrônica. Lavras: UFLA/ FAEPE, 2004. 88p.

BRASIL. Ministério da Agricultura e Reforma Agrária. Normais climatológicas de 1961- 1990. Brasília, 1992. 84p.

BUKATSCH, F. Bemerkungen zur doppelfärbung astrablausafranin. Mikrokosmos, Stuttgart. v.61, n.8, p.255, 1972.

COSTA, L.C.B. et al. Effects of coloured shade netting on the vegetative development and leaf structure of Ocimum selloi. Bragantia, v.69, n.2, p.349-359, 2010. Disponível em: <http://www. scielo.br/scielo.php?pid=S0006-87052010000200012\&script $=$ sci arttext>. Acesso em: 04 maio 2013. doi: S0006-87052010000200012.

FERREIRA, E.A. et al. Adubação fosfatada e potássica na formação de mudas de tamarindeiro. Scientia Agraria, v.9, n.4, p.475-480, 2008. Acesso em: 12 maio 2014

FERREIRA, D.F. Sisvar a computer statistical analysis system. Ciência e Agrotecnologia, v.35, n.6, p.1039-1042, 2011. Disponível em: <http://www.scielo.br/ scielo.php?pid=S1413$70542011000600001 \&$ script $=$ sci arttext $>$. Acesso em: 15 abr 2013. doi: S1413-70542011000600001.

GÓES, G.B. et al. Utilização de húmus de minhoca como substrato na produção de mudas de tamarindeiro. Revista Verde, v.6, n.4, p.125-131, 2011. Disponível em: <http://gvaa.dominiotemporario. com/revista/index.php/RVADS/article/viewFile/495/pdf 290>. Acesso em: 12 maio 2014.

HUNSCHE, M. et al. Effects of $\mathrm{NaCl}$ on surface properties, chlorophyll fluorescence and light remission, and cellular compounds of Grewia tenax (Forssk.) Fiori and Tamarindus indica L. leaves. Plant Growth Regulation, v.61, p.253-263, 2010a. Disponível em: $<$ http://link.springer.com /article/10.1007\%2Fs10725-010-9473-x>. Acesso em: 12 dez. 2013.

HUNSCHE, M. et al. Does the microclimate under hail nets influence micromorphological characteristics of apple leaves and cuticles? Jornal of Plant Physiology, v.167, p.974-980, 2010 b. Disponível em: <http://www.sciencedirect.com/science/article/pii/ S01761617100 00994>. Acesso em: 16 dez. 2013.

JOHANSEN, D.A. Plant microtechnique. New York: McGrawHill, 1940. 523p.

KARNOVSKY, M.J. A formaldehyde-glutaraldehyde fixative of high osmolality for use in eletron microscopy. Journal of Cell Biology, v.27, n.15, p.137-138, 1965.
KHAN, P.S.S.V. et al. Growth and net photosynthetic rates of Eucalyptus tereticornis Smith under photomixotrophic and various photoautotrophic micropropagation conditions. Plant Cell, Tissue and Organ Culture, v.71, n.2, p.141-146, 2002. Disponível em: <http://link.springer.com/article/10.1023\%2FA\% 3A1019935208418>. Acesso em: 12 abr. 2013.

LEE, D.W. et al. Effects of irradiance and spectral quality on leaf structure and function in seedlings of two southeast Asian Hopea (Dipterocarpaceae) species. American Journal of Botany, v.87, n.4, p.447-455, 2000. Disponível em: <http://www.amjbot. org/content/87/4/447.short>. Acesso em: 09 abr. 2014.

MARTINS, J.R. et al. Anatomia foliar de plantas de alfavacacravo cultivadas sob malhas coloridas. Ciência Rural, v.39, n.1, p.82-87, 2009. Acesso em: 17 maio 2013.

OLIVEIRA, M.I. et al. Características biométricas, anatômicas e fisiológicas de Artemisia vulgaris L. cultivada sob telas coloridas. Revista Brasileira de Plantas Medicinais, v.11, n.1, p.56-62, 2009. Acesso em: 15 dez. 2013.

OREN-SHAMIR, M. et al. Coloured shade nets can improve the yield and quality of green decorative branches of Pittosporum variegatum. Journal of Horticultural Science \& Biotechnology, v.76, n.3, p.353-361, 2001. Disponível em: $<$ http://polyphane.com/files/c83bb8010464603276525f6275773 3ad.pdf>. Acesso em: 28 abr. 2013.

ROBARDS, A.W. An introduction to techniques for scanning electron microscopy of plant cells. In: HALL, J.L. (Ed.). Electron microscopy and cytochemistry of plant cells. New York: Elsevier, 1978. p.343-444.

ROSSATTO, D.R. et al. Características estomáticas de pares congenéricos de cerrado e mata de galeria crescendo numa região transicional no Brasil central. Acta Botanica Brasilica, v.23, n.2, p.499-508, 2009. Disponível em: <http://www.scielo.br/pdf/ abb/v23n2/v23n2a21.pdf $>$. Acesso em: 16 jul. 2013.

SHAHAK, Y. et al. Colornets: crop protection and light-quality manipulation in one technology. Acta Horticulturae, n.659, p.143-151, 2004. Disponível em: <http://www.actahort.org/ books/659/659 17.htm>. Acesso em: 19 dez. 2013.

SILVA, R.A.L. et al. Leaf anatomy of genotypes of banana plant grown under coloured shade nets. African Journal of Biotechnology, v.13, n.23, p.2359-2366, 2014. Acesso em: 30 jul. 2014.

SILVA JÚNIOR, J.M. et al. Variações anatômicas de Laelia purpurata var. cárnea cultivada in vitro sob diferentes intensidades e qualidade espectral da luz. Ciência Rural, v.42, n.3, p.480-486, 2012. Acesso em: 1 set. 2013. doi:101590/ S0103-84782012000300015.

SOLOMAKHIN, A.; BLANKE, M. The microclimate under coloured hailnets affects leaf and fruit temperature, leaf anatomy, vegetative and reproductive growth as well as fruit colouration in apple. Annals of Applied Biology, v.156, p.121-136, 2010. Acesso em: 20 dez. 2013.

SOUSA, D.M.M. et al. Caracterização morfológica de frutos e sementes e desenvolvimento pós-seminal de Tamarindus indica L. - Leguminosae: Caesalpinioideae. Revista Árvore, v.34, n.6, p.1009-1015, 2010. Acesso em: 24 ago. 2013. 
SOUZA, M.D. et al. Estudo etnobotânico de plantas medicinais na comunidade São Gonçalo Beira Rio, Cuiabá, MT. Biodiversidade, v.9, n.1, p.91-100, 2010. Disponível em: <http://200. 129.241.78/ojs/index. php/biodiversidade/article/view/104>. Acesso em: 04 dez. 2013.

SURALKAR, A.A. et al. Evaluation of anti-inflammatory and analgesic activities of Tamarindus indica seeds. Intern. Journal of Pharmaceutical Sciences and Drug Research, v.4, n.3, p.213217, 2012. Disponível em: <http://pharmacologia.co.uk/abstract. php?doi=pharmacologia.2013.117.125>. Acesso em: 01 set. 2013.

TAIZ, L.; ZEIGER, E. Fisiologia vegetal. 5.ed. Porto Alegre: Artmed, 2013. 918p.
TRIPATHI, S.; MONDAL, A.K. Taxonomic diversity in epidermal cells (stomata) of some selected Anthophyta under the order Leguminales based on numerical analysis: a systematic approach. International Journal of Science and Nature, v.3, n.4, p.788798, 2012. Disponível em: <http://www.academia.edu/4107069/>. Acesso em: 30 ago. 2013.

WESTON, E. et al. Light quantity controls leaf-cell and chloroplast development in Arabidopsis thaliana wild type and blue-lightperception mutants. Planta, v.211, p.807-815, 2000. Disponível em: <http://link.springer.com/article/10.1007/s004250000392>. Acesso em: 07 abr. 2014. 